\title{
Flow Activates an Endothelial Potassium Channel to Release an Endogenous Nitrovasodilator
}

\author{
John P. Cooke, ${ }^{*}$ Eugene Rossitch, Jr., ${ }^{\star}$ Nancy A. Andon, ${ }^{\star}$ Joseph Loscalzo, ${ }^{\star}$ and Victor J. Dzau* \\ ${ }^{*}$ Division of Cardiovascular Medicine, Stanford University School of Medicine, Stanford, California 94305 , \\ and the ${ }^{\ddagger}$ Brigham and Women’s Hospital, Boston, Massachusetts 02115
}

\begin{abstract}
Flow-mediated vasodilation is endothelium dependent. We hypothesized that flow activates a potassium channel on the endothelium, and that activation of this channel leads to the release of the endogenous nitrovasodilator, nitric oxide. To test this hypothesis, rabbit iliac arteries were perfused at varying flow rates, at a constant pressure of $60 \mathrm{~mm} \mathrm{Hg}$. Increments in flow induced proportional increases in vessel diameter, which were abolished by $\mathbf{L}, \boldsymbol{N}$-mono-methylarginine (the antagonist of nitric-oxide synthesis). Barium chloride, depolarizing solutions of potassium, verapamil, calcium-free medium, and antagonists of the $\mathrm{K}_{\mathrm{Ca}}$ channel (charybdotoxin, iberiotoxin) also blocked flow-mediated vasodilation. Conversely, responses to other agonists of endothelium-dependent and independent vasodilation were unaffected by charybdotoxin or iberiotoxin. To confirm that flow activated a specific potassium channel to induce the release of nitric oxide, endothelial cells cultured on microcarrier beads were added to a flow chamber containing a vascular ring without endothelium. Flow-stimulated endothelial cells released a diffusible vasodilator; the degree of vasorelaxation was dependent upon the flow rate. Relaxation was abrogated by barium, tetraethylammonium ion, or charybdotoxin, but was not affected by apamin, glybenclamide, tetrodotoxin, or ouabain.

The data suggest that transmission of a hyperpolarizing current from endothelium to the vascular smooth muscle is not necessary for flow-mediated vasodilation. Flow activates a potassium channel (possibly the $K_{\mathrm{Ca}}$ channel) on the endothelial cell membrane that leads to the release of nitric oxide. (J. Clin. Invest. 1991, 88:1663-1671.) Key words: Shear stress • endothelium-derived relaxing factor $\bullet$ nitric oxide
\end{abstract}

\section{Introduction}

As blood flow increases through a conduit artery, the vessel dilates (1). This phenomenon is directly dependent upon changes in flow, rather than pressure, and is mediated by a nonneurogenic local mechanism (2). The mechanism of flowmediated vasodilation is not well understood. Recently a number of groups have provided evidence that flow-mediated vasodilation is dependent upon an intact endothelium (3-6). These

Address correspondence to Dr. John P. Cooke, Division of Cardiovascular Medicine, CVRC, Stanford University School of Medicine, Stanford, CA 94305. 1991.

Received for publication 24 January 1990 and in revised form 8 July

J. Clin. Invest.

(C) The American Society for Clinical Investigation, Inc.

$0021-9738 / 91 / 11 / 1663 / 09 \$ 2.00$

Volume 88, November 1991, 1663-1671 investigators have proposed that vasodilation is mediated by the endothelium-derived relaxing factor (nitric oxide), first described by Furchgott and Zawadzki (7). Other investigators have found specific ionic channels within the endothelial cells to be activated by mechanical deformation of the membrane $(8,9)$. Oleson et al. proposed that flow-mediated vasodilation may be partly due to activation of an inwardly rectifying potassium channel within the endothelium; the resulting hyperpolarization is transmitted through gap junctions to the underlying smooth muscle to contribute to the vasodilation (9).

In a previous investigation, we found that endothelial cells exposed to shear stress released a diffusible vasodilator (10). This endogenous vasodilator had the characteristics of nitric oxide, in that the vasodilation was blocked by hemoglobin, methylene blue, and L, $N$-monomethylarginine. To link our observations with those of Oleson et al., we proposed a unifying hypothesis that flow activates a potassium channel on the endothelium, and that activation of this channel leads to the release of the endogenous nitrovasodilator, nitric oxide. The present investigation was designed to test this hypothesis.

\section{Methods}

Preparation of blood vessels. New Zealand white female rabbits weighing 2-3 kg were anesthetized with intravenous sodium pentobarbital $(30 \mathrm{mg} / \mathrm{kg})$. The thoracic aorta and iliac arteries were excised and the tissue placed in cold physiologic saline solution of the following composition (mM): $\mathrm{NaCl}, 118.3 ; \mathrm{KCl}, 4.7 ; \mathrm{CaCl}_{2}, 2.5 ; \mathrm{MgSO}_{4}, 1.2 ;$ $\mathrm{KH}_{2} \mathrm{PO}_{4}, 1.2 ; \mathrm{NaHCO}_{3}, 25.0$; calcium disodium edetate, 0.026; and glucose, 11.1. The vessels were cleaned of adherent connective tissue and the aorta was cut into rings ( $5 \mathrm{~mm}$ in length) for study in the organ and flow chamber experiments (below). Side branches of the iliac artery were occluded using electrocautery, and the vessel cut into $15-\mathrm{mm}$ segments for study in the arteriograph (below). In some aortic rings, the endothelium was removed by gentle rubbing with a watchmaker's forceps inserted into the lumen.

Organ chamber studies. To study pharmacological responses in the absence of flow, rings of rabbit thoracic aorta were suspended in organ chambers filled with $25 \mathrm{ml}$ of physiologic saline solution $\left(37^{\circ} \mathrm{C}\right)$ aerated with $95 \% \mathrm{O}_{2} / 5 \% \mathrm{CO}_{2}$. Rings were connected to force transducers (FTO3C; Grass Instrument Co., Quincy, MA) and changes in isometric force were recorded continuously (Grass polygraph 79B). Over a 90min period the vascular rings were stretched to the optimal point of their length-tension relationship (determined by periodically stimulating the tissue with $10^{-6} \mathrm{M}$ norepinephrine). Subsequently, in all rings the $\mathrm{EC}_{50}$ (concentration of drug inducing a half-maximal response) for norepinephrine was determined by exposing the tissues to increasing concentrations of norepinephrine, added to the organ chamber in half$\log$ increments in a cumulative manner. After a maximal response to norepinephrine was obtained, the vascular rings were washed repeatedly with fresh physiologic saline solution until tension returned to the previous baseline value. Tissues were then exposed to antagonists or vehicle controls for $20 \mathrm{~min}$. To study vasodilating agents, rings were then contracted by the $\mathrm{EC}_{50}$ concentration of norepinephrine. After a stable contraction was obtained, the tissue was exposed to cumulative 
increases in concentration of the vasodilator in half-log increments; relaxations are expressed as a percentage of the response to the $\mathrm{EC}_{50}$ concentration of norepinephrine.

Arteriograph studies. To study the effect of changes in flow upon vessel diameter, iliac arteries were mounted in an arteriograph (Living Systems Instrumentation, Burlington, VT), filled with oxygenated physiologic saline solution at $37^{\circ} \mathrm{C}$. Both ends of the vessel were cannulated by glass capillary tubing for perfusion with oxygenated physiologic saline solution. The proximal cannula was connected to a syringe (driven by a pressure-servo system) that delivered the perfusate at a constant luminal pressure of $60 \pm 2 \mathrm{~mm} \mathrm{Hg}$. The outflow cannula was connected to a flexible plastic tubing that was threaded through a thumbscrew clamp. The resistance of the outflow tubing was varied by adjusting the thumbscrew clamp. This system permitted rapid changes in flow $(0-5 \mathrm{ml} / \mathrm{min})$ at constant pressure to be correlated with simultaneous measurement of vessel diameter. Changes in vessel diameter were monitored by a video system consisting of a Leitz inverted microscope, RCA video camera (RCA Electro-Optics \& Devices, Lancaster, PA), and video monitor. Midplane transverse diameters were measured with a caliper accurate to $0.01 \mathrm{~mm}$ directly applied to the video screen. Absolute calibration was obtained before each experiment with a micrometer grid placed at the level of the vessel. With this system, highly accurate measurements of vessel diameter are obtained (11). The images were stored on VHS tape using a Panasonic VHS recorder. Before studying the effects of flow on the vessel, perfusate-containing antagonists or vessel control was instilled intraluminally and incubated with the tissue for 20 min under no-flow conditions. Subsequently the vessel was exposed to $60 \pm 2 \mathrm{~mm} \mathrm{Hg}$ pressure under no-flow conditions, and then contracted by adding norepinephrine $\left(10^{-5} \mathrm{M}\right)$ or potassium chloride $(80 \mathrm{mmol})$ to the external bath. When the vessel diameter stabilized at a pressure of $60 \pm 2 \mathrm{~mm} \mathrm{Hg}$, flow was initiated. Flow was measured by collecting the outflow from the distal cannula and weighing it on a Mettler scale. Vessel diameter was measured after $1 \mathrm{~min}$ of flow stimulus. For each condition to which the vessel was exposed (i.e., control solution or antagonist), the flow stimulus was repeated two to four times and measurements of vessel diameter and flow rate were averaged. To determine the response to receptor-mediated vasodilators, after contraction to norepinephrine, perfusate containing the vasodilator was instilled intraluminally and incubated with the tissue for $5 \mathrm{~min}$ in the absence of flow at a pressure of $60 \pm 2 \mathrm{~mm} \mathrm{Hg}$, and measurements of vessel diameter were repeated.

Microcarrier endothelial cell cultures. Endothelial cells were isolated from bovine aorta using established techniques and were cultured on a microcarrier system of negatively charged plastic beads (Biosilon ${ }^{R}$; Nunc, Roskilde, Denmark) as previously described (12). Bovine aorta endothelial cells were grown in DME containing $25 \mathrm{M}$ Hepes and $10 \%$ FCS. DME was composed of (mM): $\mathrm{NaCl}, 109 ; \mathrm{KCl}, 5.5 ; \mathrm{CaCl}_{2}, 1.8$; $\mathrm{MgSO}_{4}, 1.7 ; \mathrm{NaHCl}_{3}, 51 ; \mathrm{NaH}_{2} \mathrm{PO}_{4}, 1.0 ; \mathrm{Fe}\left(\mathrm{NO}_{3}\right) \cdot 9 \mathrm{H}_{2} \mathrm{O}, 3.6 \times 10^{-3}$; glucose, 30; sodium pyruvate, 1.0; and phenosulfonphthalein, 4.2 $\times 10^{-2}$. Cells were cultured for $1 \mathrm{wk}$, placed on microcarrier beads, and then grown to confluence. Before use, the cells (on microcarrier beads) were resuspended in fresh DME without calf serum. Cells were then drawn up and permitted to settle to a packed volume of $0.4 \mathrm{ml}$ in a $1-\mathrm{ml}$ Eppendorf pipette tip, and transferred to the flow chamber for study.

Flow chamber studies. If flow-mediated vasodilation is largely due to a wave of hyperpolarization spreading from the endothelium to the underlying vascular smooth muscle, intercellular connections (i.e., gap junctions) would be required. Conversely, if flow-mediated vasodilation is largely due to the release of a diffusible factor, intercellular connections would not be necessary. To test the hypothesis that cell contact with the vascular smooth muscle is essential for vasorelaxation by flow-stimulated endothelial cells, a flow chamber was used $(10,13,14)$. This apparatus is a small jacketed glass chamber $\left(2 \mathrm{~cm}^{3}\right.$ volume, $1.5 \mathrm{~cm}$ i.d.), containing a stainless steel stir bar, and is affixed to a magnetic stirrer (Thermix 120MR; Fisher Scientific Co., Pittsburgh, PA). The chamber is filled with oxygenated physiologic saline solution at $37^{\circ} \mathrm{C}$. A vascular ring mechanically denuded of endothelium is suspended on two stainless steel prongs, one attached to a force transducer and the other to a displacement micrometer. Changes in isometric force are recorded continuously (Grass polygraph 79B). The vascular ring is immersed in the flow chamber and contraction induced by the addition of norepinephrine $\left(10^{-6} \mathrm{M}\right)$ to the solution in the presence of antagonist or vehicle control. Once the contraction has stabilized, bovine aortic endothelial cells on microcarrier beads (EC) are added to the chamber. Vortical flow is then induced by activation of the magnetic stirrer. The flow velocities generated by this system (measured by laser Doppler velocimetry) induce endothelial shear stresses of $0.1-0.4 \mathrm{dyn} / \mathrm{cm}^{2}$. This shear stress is well within the range of values attained in conduit vessels in vivo. Under these conditions, endothelial cells release a vasodilator that also inhibits platelet aggregation $(10,13,14)$.

Drugs. The following drugs were used: acetylcholine chloride, apamin, barium chloride, glybenclamide, norepinephrine hydrochloride, ouabain octahydrate, saponin, sodium nitroprusside, tetrodotoxin, verapamil hydrochloride (Sigma Chemical Co., St. Louis, MO), sodium pentobarbital (Abbott Laboratories, North Chicago, IL), L, $N$-monomethyl-arginine sulphonate (Calbiochem-Behring Corp., San Diego, CA), tetraethylammonium chloride (Kodak Laboratory and Specialty Chemicals, Rochester, NY), and charybdotoxin and iberiotoxin (kindly provided by Dr. Maria Garcia, Merck Sharpe \& Dohme Research Laboratories, West Point, PA). Glybenclamide and L, $\mathrm{N}$-monomethylarginine were dissolved in $50 \%$ ethanol; all other agents were soluble in distilled water or physiological saline solution. In experiments employing L, $\mathrm{N}$-monomethylarginine or glybenclamide, the control vessel was exposed to the same concentration of vehicle. When barium chloride was employed, the physiologic saline solution was modified to increase the solubility of barium by replacing $\mathrm{KH}_{2} \mathrm{PO}_{4}$ and $\mathrm{MgSO}_{4}$ with equimolar concentrations of $\mathrm{KCl}$ and $\mathrm{MgCl}$, respectively. In experiments employing $\mathrm{BaCl}$, the control vessel was exposed to this modified saline solution. In flow chamber experiments employing ouabain, endothelial cells were separately incubated for $20 \mathrm{~min}$ with physiologic saline solution alone, or that containing ouabain $\left(5 \times 10^{-6} \mathrm{M}\right)$; the cells were then transferred to the flow chamber for study. This was done to avoid the effects of ouabain on smooth muscle tone (15).

Data analysis. In the organ and flow chamber studies, the tension remaining after exposure to vasodilators is expressed as percent of the initial contraction to norepinephrine. Responses to vasodilators were analyzed by determining the $\mathrm{EC}_{\mathbf{s o}}$ (concentration of drug-inducing half-maximal relaxation, expressed as the negative logarithm) and the maximal response (the tension remaining after maximal vasodilation, expressed as a percentage of the initial contraction to norepinephrine). All experiments in the flow and organ chambers employing antagonists were performed with simultaneous controls.

In the arteriograph, tissues were exposed to norepinephrine $\left(10^{-5}\right.$ $\mathrm{M})$, or in some experiments $\mathrm{KCl}\left(8 \times 10^{-2} \mathrm{M}\right)$. When the vessel diameter stabilized (after 20-30 min) at a luminal pressure of $60 \pm 2 \mathrm{~mm} \mathrm{Hg}$ (in the absence of flow), a baseline diameter was recorded. Changes in vessel diameter with flow are expressed as a percentage of this baseline.

Data are expressed as mean \pm SEM, and comparisons are made using paired $t$ tests; where multiple means were compared, an analysis of variance was performed followed by a Neumann-Keuls test unless stated otherwise. A $P$ value $<0.05$ was accepted as statistically significant.

\section{Results}

Arteriograph studies. After exposure to norepinephrine $\left(10^{-5}\right.$ $M)$ and at a constant pressure of $60 \pm 2 \mathrm{~mm} \mathrm{Hg}$, flow induced an increase in the diameter of the iliac artery which was directly proportional to the rate of flow (Fig. 1). Removal of the endothelium abolished the vasodilation to flow as well as that to acetylcholine $10^{-7} \mathrm{M}$, but did not affect the response to nitroglycerine (Fig. 2). The antagonist of arginine metabolism, L, $N$-monomethylarginine $\left(10^{-4} \mathrm{M}\right)$ reversed flow-mediated vasodilation to a vasoconstriction (Fig. 3). L, $N$-monomethylarginine did not affect contractions to norepinephrine (Table I). 


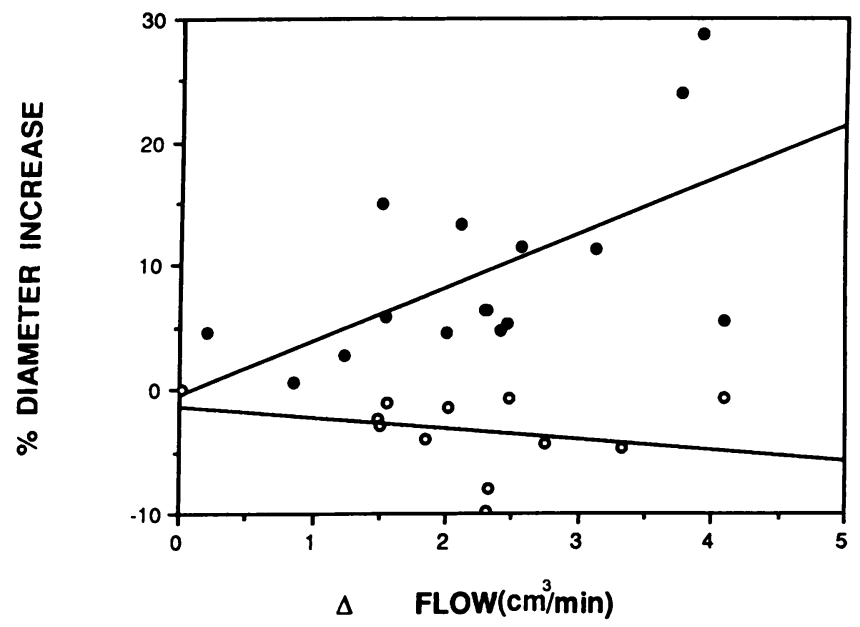

Figure 1. Flow-mediated vasodilation is proportional to the flow rate, and is blocked by charybdotoxin (arteriograph studies). Increments in flow-induced proportional increments in vessel diameter under control conditions ( $\bullet$; linear regression values of $r=0.66, P=0.003$ ). In the presence of charybdotoxin $\left(10^{-8} \mathrm{M}\right)$, increments in flow were no longer associated with increases in vessel diameter (o; linear regression values of $r=-0.33, P=\mathrm{NS}$ ).

Flow-mediated vasodilation was also reversed by barium chloride $\left(10^{-3} \mathrm{M}\right)$ and by depolarizing solutions of potassium chloride $\left(8 \times 10^{-2} \mathrm{M}\right)$ (Fig. 3). The abolition of flow-mediated vasodilation was not due to changes in vascular smooth muscle tone, since contractions to norepinephrine were not altered by barium (Table I). Likewise, when depolarizing solutions of potassium chloride were substituted for norepinephrine the contractions induced were not different from those to norepinephrine (Table I).

Nanomolar concentrations of iberiotoxin or charybdotoxin also reversed flow-mediated vasodilation (Figs. 1 and 3). Conversely, vasodilation to acetylcholine chloride $\left(10^{-7} \mathrm{M}\right)$ and sodium nitroprusside $\left(10^{-5} \mathrm{M}\right)$ was preserved in the presence of charybdotoxin $10^{-8} \mathrm{M}$ (data not shown). Likewise, iberiotoxin $\left(10^{-9} \mathrm{M}\right)$ did not impair vasodilation to acetylcholine chloride, $10^{-7} \mathrm{M}(17.8 \pm 4.1$ vs. $12.0 \pm 2.8 \%$ increase in vessel diameter, control vs. experimental group, $P=\mathrm{NS}$ ). Low concentrations of verapamil $\left(10^{-9} \mathrm{M}, 10^{-8} \mathrm{M}\right)$ that did not affect the contraction to norepinephrine (Table I) also inhibited the flow response (Fig. 4). The reversal of flow-mediated vasodilation by a higher concentration of verapamil $\left(10^{-7} \mathrm{M}\right)$ was not due to an inability of the vessel to relax further, since addition of verapamil $\left(10^{-5} \mathrm{M}\right)$ in the absence of flow induced a further increase in the vessel diameter $(11.8 \pm 4.7 \%, n=4)$. This effect of verapamil was probably due to inhibition of extracellular calcium entry, since removal of calcium from the perfusate also blocked flow-mediated vasodilation (Fig. 5). Abolition of flowmediated vasodilation by the potassium channel antagonists or by the inhibitor of nitric oxide synthesis was not due to differences in flow rates or changes in vessel response with time (Table I, Fig. 3). With the exception of charybdotoxin and the

\section{FLOW MEDIATED VASODILATION ENDOTHELIUM DEPENDENT}

INTACT ENDOTHELUUM

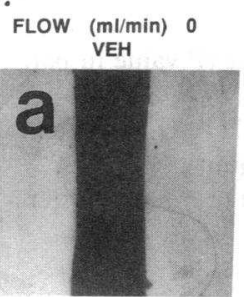

VEH
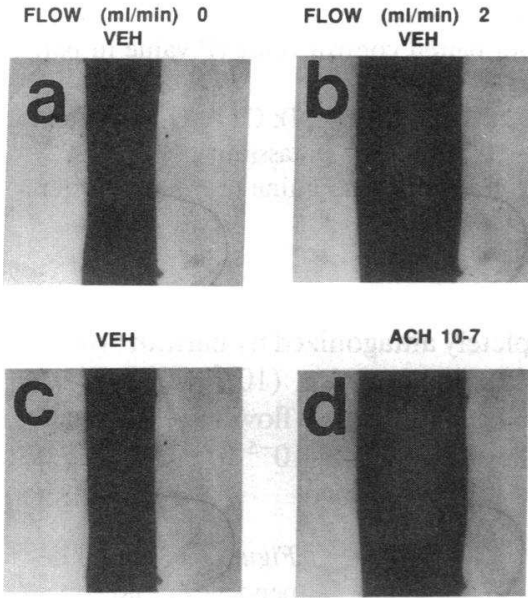

ACH 10-7
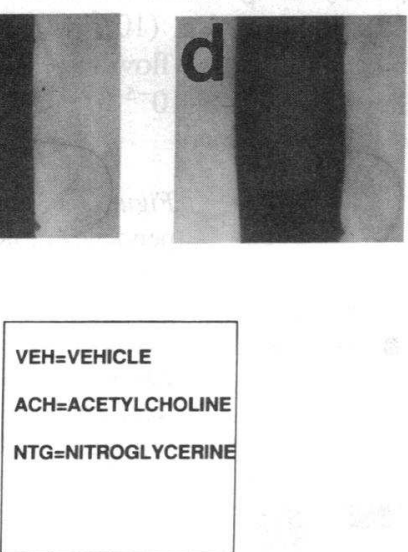

ENDOTHELIAL DENUDATION

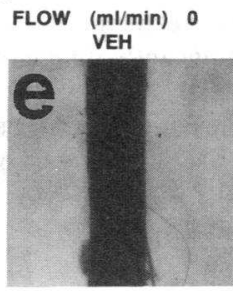

VEH
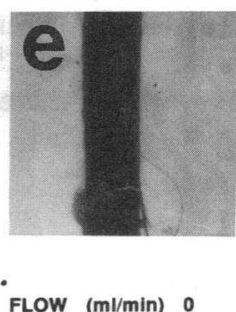

VEH

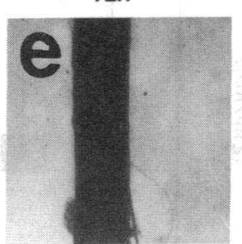

FLOW $(\mathrm{ml} / \mathrm{min}) 2$ VEH

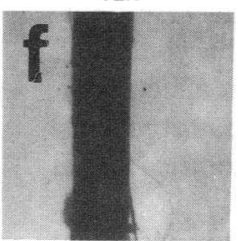

ACH 10-7

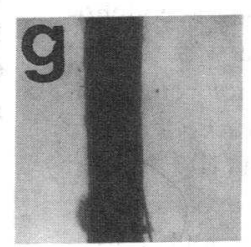

FLOW $(\mathrm{ml} / \mathrm{min}) 2$ NTG 10-5

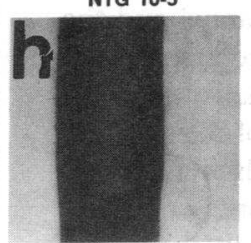

Figure 2. Photographs of original records from one experiment, representative of five, demonstrating that flow-mediated vasodilation is endothelium dependent.

Intact endothelium (first two columns): (a) Rabbit iliac artery segment contracted by norepinephrine $10^{-6} \mathrm{M}$. Intraluminal perfusate flow is $0 \mathrm{ml} / \mathrm{min}$. Intraluminal pressure is $60 \mathrm{~mm} \mathrm{Hg}$, and was held at this level throughout the experiment.

(b) Immediately after recording the previous photograph, the flow of perfusate (physiological saline solution; VEH) was increased to $2 \mathrm{ml} / \mathrm{min}$ for 2 min and this photograph recorded. The vessel has visibly dilated. (c) Flow is discontinued and the vessel returns to its preconstricted diameter over $30 \mathrm{~min}$. (d) Immediately after recording the previous photograph, perfusate containing acetylcholine $10^{-7} \mathrm{M}$ is instilled into the lumen. The vessel has visibly dilated. After endothelial denudation (last two columns): (e) After these observations were made, the endothelium of this vessel was removed using saponin. The vessel was again contracted by norepinephrine $10^{-6} \mathrm{M}$, and this photograph was taken when the contraction had stabilized at an intraluminal flow of $0 \mathrm{ml} / \mathrm{min}$ and a pressure of $60 \mathrm{mmHg}$. (This record is repeated in the third column for ease of comparison to subsequent records.) $(f)$ Immediately after recording the previous photograph the flow of perfusate was increased to $2 \mathrm{ml} / \mathrm{min}$ for $2 \mathrm{~min}$ and this photograph taken. Flow-mediated vasodilation has been abolished. (g) Subsequently the vessel is perfused with physiological saline solution containing ace-

tylcholine $10^{-7} \mathrm{M}$. The endothelium-dependent vasodilation to this agonist has been abolished. $(h)$ Subsequently the vessel is perfused with physiological saline solution containing nitroglycerin $\left(10^{-5} \mathrm{M}\right)$. The response to this exogenous nitrovasodilator is preserved. 


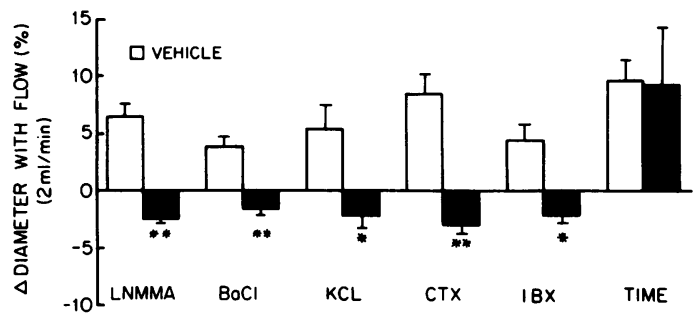

Figure 3. Flow-mediated vasodilation is abolished by inhibitors of potassium channel activity and of nitric oxide synthesis. Pressurized perfused iliac arteries contracted by norepinephrine $10^{-5} \mathrm{M}$ dilated in response to increases in flow. After flow was discontinued, perfusate containing drugs or solvent controls was instilled intraluminally and incubated with the vessel for 20 min under no-flow conditions. The vessel was then exposed to the flow stimulus again. When the perfusate contained $\mathrm{L}, \mathrm{N}$-monomethylarginine $10^{-4} \mathrm{M}(L N M M A)$, barium chloride $10^{-3} \mathrm{M}(\mathrm{BaCl})$, charybdotoxin $10^{-8} \mathrm{M}(C T X)$, or iberiotoxin $10^{-9} \mathrm{M}(I B X)$, flow-mediated vasodilation was blocked (dark bars) in comparison to vehicle controls (open bars). When potassium chloride $8 \times 10^{-2} \mathrm{M}(\mathrm{KCl}$, dark bar) was substituted for norepinephrine (open bar), flow-mediated vasodilation did not occur. Time (first flow stimulation, open bar; second flow stimulation, dark bar) had no effect on vascular response. For each condition to which the vessel was exposed, the flow stimulus was repeated two to four times, and measurements of flow rates and vessel diameter averaged for each vessel (see Table I). *Significantly different from paired control, $P=0.01$. ${ }^{* *}$ Significantly different from paired control, $P<0.001$.

highest concentration of verapamil $\left(10^{-7} \mathrm{M}\right)$, the antagonists did not affect vessel diameter before flow, in comparison to vehicle controls (Table I).

Organ chamber studies. To determine whether potassium channel antagonists affect endothelium-dependent or independent relaxations of rabbit thoracic aorta in the absence of flow, responses of vascular rings (with endothelium) were studied in the organ chamber. Sodium nitroprusside induced concentration-dependent relaxations of vascular rings that were unaffected by tetraethyl-ammonium ion, barium, or charybdotoxin (Table II). Likewise, iberiotoxin $\left(10^{-9} \mathrm{M}\right)$ did not affect relaxation to nitroglycerin (Table III). Contractions to norepinephrine were unaffected by barium or the other antagonists (Tables II and III).

Acetylcholine is known to induce relaxations in vitro that are dependent upon the presence of endothelium (7). In the presence of tetraethylammonium ion, relaxations to acetylcholine were observed but the maximum response was slightly decreased (Table II). Barium ion, charybdotoxin, or verapamil had no effect on the $\mathrm{EC}_{50}$ or maximal response to acetylcholine chloride (Tables II and IV). Likewise, iberiotoxin $\left(10^{-9} \mathrm{M}\right)$ did not affect endothelium-dependent relaxation to acetylcholine chloride, adenosine diphosphate, or calcium ionophore (Table III).

Flow chamber studies. The arteriograph studies suggested that activation of an endothelial potassium channel and the release of nitric oxide were necessary for flow-mediated vasodilation. To determine whether flow-mediated activation of a potassium channel plays a role in the release of nitric oxide, endothelial cells cultured on microcarrier beads were stimulated by flow in the absence or presence of a variety of potassium channel antagonists. Under control conditions, relaxation of the ring occurred, the degree of which was directly related to the endothelial shear stress induced by flow (Fig. 6);
Table I. Vessel Diameter and Flow Rates in the Presence of Antagonists (Arteriograph Studies)

\begin{tabular}{|c|c|c|}
\hline Condition & $\begin{array}{l}\text { Vessel diameter } \\
\text { before flow }\end{array}$ & Flow rate \\
\hline & $\mu m^{*}$ & $\mathrm{ml} / \mathrm{min}^{*}$ \\
\hline Control $(n=4)$ & $1,380 \pm 70$ & $2.9 \pm 0.4$ \\
\hline Time control $(n=4)$ & $1,450 \pm 70$ & $2.8 \pm 0.6$ \\
\hline Control $(n=3)$ & $1,260 \pm 50$ & $1.7 \pm 0.5$ \\
\hline \multicolumn{3}{|c|}{ In the presence of LNMMA } \\
\hline Control $(n=5)$ & $1,320 \pm 30$ & $2.4 \pm 0.4$ \\
\hline \multicolumn{3}{|l|}{ In the presence of $\mathrm{BaCl}$} \\
\hline$(n=5)$ & $1,290 \pm 50$ & $2.5 \pm 0.3$ \\
\hline Control $(n=3)$ & $1,420 \pm 160$ & $3.7 \pm 0.1$ \\
\hline \multicolumn{3}{|l|}{ In the presence of $\mathrm{KCI}$} \\
\hline$(n=3)$ & $1,360 \pm 180$ & $2.9 \pm 0.4$ \\
\hline Control $(n=5)$ & $1,630 \pm 40$ & $2.2 \pm 0.3$ \\
\hline \multicolumn{3}{|l|}{ In the presence of CTX } \\
\hline$(n=5)$ & $1,460 \pm 40^{5}(P=0.004)$ & $2.1 \pm 0.3$ \\
\hline Control $(n=4)$ & $1,340 \pm 120$ & $2.2 \pm 0.2$ \\
\hline \multicolumn{3}{|l|}{ In the presence of IBX } \\
\hline$(n=4)$ & $1,360 \pm 170$ & $2.2 \pm 0.2$ \\
\hline Control $(n=6)$ & $1,250 \pm 90$ & $2.0 \pm 0.3$ \\
\hline \multicolumn{3}{|l|}{ In the presence of } \\
\hline $\mathrm{V} 10^{-9} \mathrm{M}(n=4)$ & $1,330 \pm 120$ & $2.0 \pm 0.3$ \\
\hline $\mathrm{V} 10^{-8} \mathrm{M}(n=4)$ & $1,380 \pm 100$ & $2.0 \pm 0.3$ \\
\hline $\mathrm{V} 10^{-7} \mathrm{M}(n=4)$ & $1,380 \pm 90^{\S}(P=0.005)$ & $2.0 \pm 0.3$ \\
\hline
\end{tabular}

* Vessel diameter after exposure to norepinephrine $\left(10^{-5} \mathrm{M}\right)$ at a pressure of $60 \pm 2 \mathrm{~mm} \mathrm{Hg}$ and at a flow rate of $0 \mathrm{ml} / \mathrm{min}$. The exception is where $\mathrm{KCI}\left(8 \times 10^{-2} \mathrm{M}\right)$ was substituted for norepinephrine. In these experiments vessel diameter after exposure to norepinephrine (control) was not different from that with $\mathrm{KCl}$.

${ }^{\ddagger}$ For each condition to which the vessel was exposed, the flow stimulus was repeated two to four times, and measurements of flow rate and vessel diameter averaged.

${ }^{8}$ Significantly different from paired control value ( $P$ value in parentheses).

Abbreviations: $\mathrm{BaCl}$, barium chloride $\left(10^{-3} \mathrm{M}\right)$; CTX, charybdotoxin $\left(10^{-8} \mathrm{M}\right)$; IBX, iberiotoxin $\left(10^{-9} \mathrm{M}\right) ; \mathrm{KCl}$, potassium chloride $(8$ $\left.\times 10^{-2} \mathrm{M}\right)$; LNMMA, L, $N$-monomethylarginine $\left(10^{-4} \mathrm{M}\right)$; V, verapamil.

this relaxation was completely antagonized by barium $\left(10^{-3} \mathrm{M}\right.$; Fig. 6) or by tetraethylammonium ion $\left(10^{-3} \mathrm{M}\right.$; Table V). Charybdotoxin $\left(10^{-8} \mathrm{M}\right)$ also reversed flow-mediated relaxation (Fig. 7), whereas glybenclamide $\left(10^{-5} \mathrm{M}\right)$, tetrodotoxin

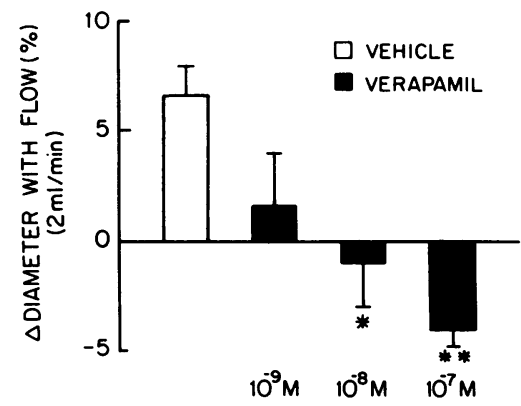

Figure 4. Calcium dependency of flow-mediated vasodilation. Same protocol as illustrated in Fig. 2. Verapamil (V; dark bars) induced a dose-dependent inhibition of the flow response when it was added to the perfusate. *, ** Significantly different from vehicle control (CTRL; open bar), ${ }^{*} P$ $<0.05,{ }^{* *} P<0.005$ 


\section{FLOW MEDIATED VASODILATON:}

\section{DEPENDENCY UPON CALCIUM AVAILABILITY}

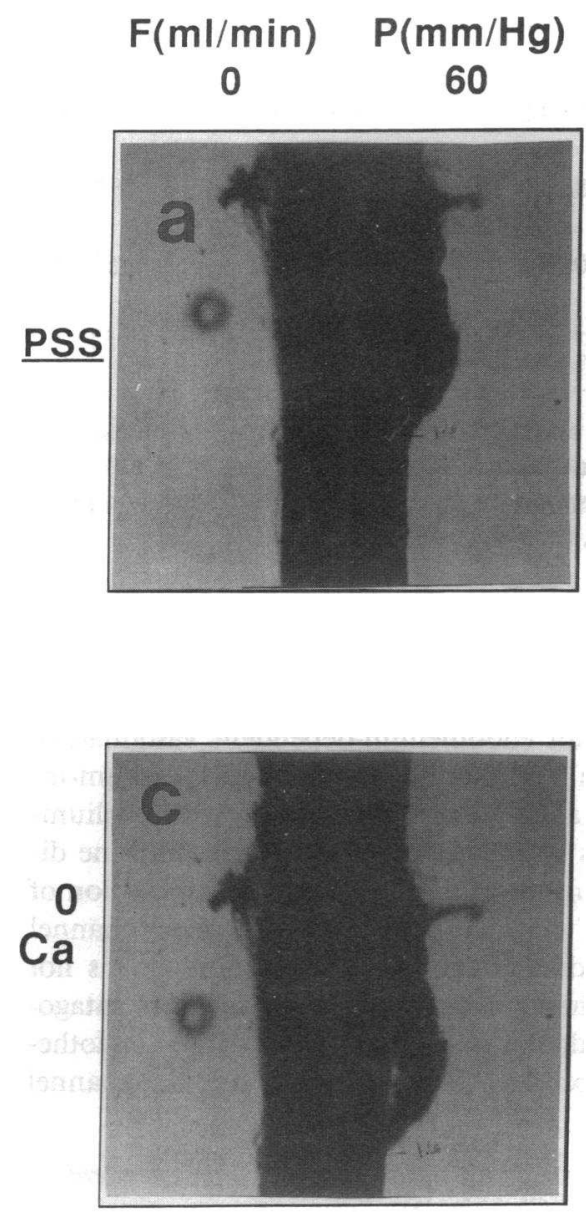

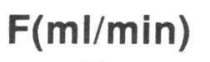

5

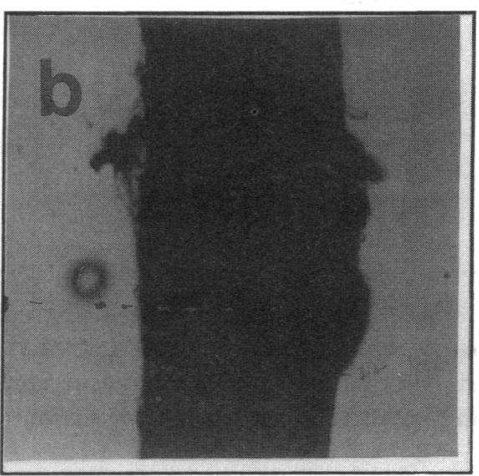

Figure 5. Photographs of original records from one experiment, representative of five, demonstrating the calcium-dependency of flow-mediated vasodilation. (a) Rabbit iliac artery segment contracted by norepinephrine $10^{-6} \mathrm{M}$. Intraluminal perfusate flow is $0 \mathrm{ml} / \mathrm{min}$. Intraluminal pressure is $60 \mathrm{~mm} \mathrm{Hg}$, and was held at this level throughout the experiment. $(b)$ Immediately after recording the previous photograph, the flow of perfusate (physiological saline solution; PSS) was increased to $5 \mathrm{ml} / \mathrm{min}$ for 2 min and this photograph recorded. The vessel has visibly dilated. $(c)$ Flow is discontinued and the vessel returns to its preconstricted diameter over $30 \mathrm{~min}$. (d) Immediately after recording the previous photograph, the flow of perfusate (calcium-free saline solution; $0 \mathrm{Ca}$ ) was increased to $5 \mathrm{ml} / \mathrm{min}$ for $2 \mathrm{~min}$ and this photograph recorded. Flow-mediated vasodilation has been abolished. In two other experiments, calcium was readded to the perfusate, and the flow response was largely restored.

$\left(10^{-7} \mathrm{M}\right)$, apamin $\left(10^{-7} \mathrm{M}\right)$, and ouabain $\left(5 \times 10^{-6} \mathrm{M}\right)$ had no effect (Table V).

\section{Discussion}

The present study demonstrates that flow induces the endothelium to synthesize and release an endogenous nitrovasodilator. More importantly, this investigation reveals for the first time that the release of this nitric oxide by flow is dependent upon activation of a potassium channel on the endothelial cell membrane. Barium or depolarizing solutions of potassium inactivate most potassium channels and are also known to inactivate the endothelial potassium channel activated by shear stress ( 9 , 16). In our investigation, these agents reversed flow-mediated vasodilation to a vasoconstriction, suggesting that a potassium channel is involved in the response. Our additional studies support the hypothesis that the channel involved in the flow response is the calcium-activated potassium $\left(\mathrm{K}_{\mathrm{Ca}}\right)$ channel. Tetraethylammonium ion $(1 \mathrm{mM})$ markedly reduces the openstate probability and single-channel conductance of the $\mathrm{K}_{\mathrm{Ca}}$ channel, whereas many other potassium channels (such as the ATP-sensitive inward-rectifier) are insensitive to this concentration of tetra-ethylammonium ion $(17,18)$. Charybdotoxin is a potent antagonist of the $\mathrm{K}_{\mathrm{Ca}}$ channel without any activity against sodium channels, L- or T-type calcium channels, or a variety of other potassium channels $(19,20)$. However, it also inhibits the voltage-dependent potassium channel found in lymphocytes; an intermediate conductance calcium-activated channel in Aplysia neurons; and, as expressed in oocytes, the Shaker channel as well as a neuronal A-type channel (20-23). Therefore, the observations that tetraethylammonium ion and charybdotoxin block flow-mediated vasodilation suggest that the $\mathrm{K}_{\mathrm{Ca}}$ channel is involved, but do not entirely rule out a role for other channels.

By contrast, iberiotoxin is highly selective for the $\mathrm{K}_{\mathrm{Ca}}$ channel and does not inhibit the other charybdotoxin-sensitive potassium channels (24). In nanomolar concentrations, iberiotoxin blocked flow-mediated vasodilation. As further evidence that the $\mathrm{K}_{\mathrm{Ca}}$ channel is involved, other potassium channel antagonists had no effect on flow-mediated vasodilation. Specifcally, glybenclamide (the antagonist of the ATP-associated potassium channel), apamin (the antagonist of the low conductance calcium-activated potassium channel), tetrodotoxin (the sodium channel antagonist which also blocks the sodium-activated potassium channel), and ouabain (the antagonist of sodium, potassium, ATPase) had no effect. The most likely expla- 
Table II. Effect of Potassium Channel Antagonists upon Endothelium-dependent and -independent Vasorelaxation (Organ Chamber Studies)

\begin{tabular}{|c|c|c|c|c|c|c|}
\hline \multirow[b]{2}{*}{ Condition } & \multicolumn{3}{|c|}{ Response ${ }^{*}$ to sodium nitroprusside } & \multicolumn{3}{|c|}{ Response* to acetylcholine } \\
\hline & Contraction $^{*}$ & $\mathrm{EC}_{30}$ & $\begin{array}{l}\text { Maximal } \\
\text { response }\end{array}$ & Contraction $^{\ddagger}$ & $\mathrm{EC}_{30}$ & $\begin{array}{l}\text { Maximal } \\
\text { response }\end{array}$ \\
\hline & $g$ & $-\log M$ & $\%$ & $g$ & $-\log M$ & $\%$ \\
\hline Control $(n=6)$ & $7.5 \pm 0.6$ & $6.5 \pm 0.3$ & 0 & $7.5 \pm 0.6$ & $7.3 \pm 1.4$ & $43 \pm 10$ \\
\hline \multicolumn{7}{|l|}{ In the presence of TEA } \\
\hline$(n=6)$ & $7.4 \pm 0.7$ & $6.5 \pm 0.8$ & $1 \pm 1$ & $6.8 \pm 0.8$ & - & $65 \pm 4^{8}$ \\
\hline \multicolumn{7}{|l|}{ In the presence of $\mathrm{BaCl}$} \\
\hline$(n=6)$ & $7.5 \pm 0.8$ & $6.6 \pm 0.4$ & 0 & $5.0 \pm 0.6$ & $7.5 \pm 0.5$ & $52 \pm 4$ \\
\hline \multicolumn{7}{|l|}{ In the presence of CTX } \\
\hline$(n=6)$ & $7.6 \pm 0.3$ & $5.8 \pm 0.9$ & 0 & $7.7 \pm 0.3$ & $7.9 \pm 0.3$ & $54 \pm 7$ \\
\hline
\end{tabular}

* Expressed as the $\mathrm{EC}_{50}$ (concentration of drug, in $-\log \mathrm{M}$, inducing a half-maximal response) and as the maximal response (the tension remaining after maximal vasodilation, expressed as a percentage of the initial contraction to norepinephrine). Where the maximal response was depressed, an $\mathrm{EC}_{50}$ was not calculated (37). ${ }^{\ddagger}$ Isometric force (measured in grams) generated in response to the $\mathrm{EC}_{50}$ concentration of norepinephrine. Significantly less relaxation in comparison to control, $P=0.05$. Abbreviations: TEA, tetraethylammonium ion $\left(10^{-3} \mathrm{M}\right)$.

nation for these results is that the high conductance calciumactivated potassium channel is involved in the flow response. Consistent with this interpretation of the data is the observation that verapamil also abolished the flow response, at concentrations that did not affect other endothelium-dependent responses. Sustained activity of the $\mathrm{K}_{\mathrm{Ca}}$ channel is known to be dependent upon extracellular calcium $(25,26)$; thus a calcium entry antagonist would be expected to interfere with the flow response if the $\mathrm{K}_{\mathrm{Ca}}$ channel plays an important role. This dependency upon extracellular calcium was confirmed by demonstrating that calcium-free perfusate did not elicit a flow-mediated vasodilation.

Charybdotoxin $\left(10^{-8} \mathrm{M}\right)$ did induce a contraction of the iliac artery, probably due to antagonism of $\mathrm{K}_{\mathrm{Ca}}$ channels present on vascular smooth muscle $(19,24,27)$. Despite this elevation of basal tone, relaxations to sodium nitroprusside (an endothelium-independent vasodilator) were preserved. Therefore,

Table III. Effect of Iberiotoxin upon Endothelium-dependent and -independent Vasorelaxation (Organ Chamber Studies)

\begin{tabular}{|c|c|c|c|c|}
\hline \multirow[b]{2}{*}{ Agent } & \multicolumn{2}{|c|}{ Control response* } & \multicolumn{2}{|c|}{$\begin{array}{l}\text { In presence of iberiotoxin } \\
\qquad\left(10^{-9} \mathrm{M}\right)^{*}\end{array}$} \\
\hline & $\mathrm{EC}_{50}$ & $\begin{array}{l}\text { Maximal } \\
\text { response }\end{array}$ & $\mathrm{EC}_{\mathbf{s 0}}$ & $\begin{array}{l}\text { Maxima } \\
\text { response }\end{array}$ \\
\hline & $-\log M$ & $\%$ & $-\log M$ & $\%$ \\
\hline NTG $(n=4)$ & $7.5 \pm 0.6$ & $11 \pm 4$ & $7.2 \pm 0.5$ & $8 \pm 4$ \\
\hline $\operatorname{ACh}(n=4)$ & $7.7 \pm 0.1$ & $54 \pm 8$ & $7.7 \pm 0.3$ & $33 \pm 10$ \\
\hline $\operatorname{ADP}(n=4)$ & $6.8 \pm 0.4$ & $15 \pm 12$ & $6.2 \pm 0.5$ & $22 \pm 10$ \\
\hline $\mathrm{A} 23187(n=4)$ & $6.5 \pm 0.3$ & $63 \pm 2$ & $6.7 \pm 0.5$ & $49 \pm 10$ \\
\hline
\end{tabular}

* Vasodilatory responses are expressed as the $\mathrm{EC}_{50}$ (concentration of drug in $-\log M$ inducing a half-maximal response) and as the maximal response (the tension remaining after maximal vasodilation, expressed as a percentage of the initial contraction to norepinephrine). Contraction to norepinephrine in the presence of iberiotoxin $\left(10^{-9}\right.$ M) was not different from vehicle control $(3.9 \pm 0.9$ vs. $3.6 \pm 1.2 \mathrm{~g}, n$ $=4, P=\mathrm{NS}$ ).

Abbreviations: A2317, calcium ionophore A23187; ACh, acetylcholine chloride; NTG, nitroglycerine. antagonism of flow-mediated vasodilation by charybdotoxin was not due to a direct effect on the vascular smooth muscle. Furthermore, charybdotoxin did not block relaxations to acetylcholine chloride (an endothelium-dependent vasodilator). Likewise, iberiotoxin $\left(10^{-9} \mathrm{M}\right)$ did not affect endothelium-independent vasorelaxation to nitroglycerine, or endotheliumdependent responses to acetylcholine chloride, adenosine diphosphate, or calcium ionophore. A plausible explanation of these findings is that the calcium-activated potassium channel is involved in transduction of the flow stimulus, but is not required for the synthesis or release of nitric oxide since antagonism of this channel does not affect receptor-mediated endothelium-dependent relaxation. Thus, opening of the $\mathrm{K}_{\mathrm{Ca}}$ channel

Table IV. Effect of Verapamil upon Endothelium-dependent Vasorelaxation (Organ Chamber Studies)

\begin{tabular}{|c|c|c|c|}
\hline \multirow[b]{2}{*}{ Condition } & \multicolumn{3}{|c|}{ Response* to acetylcholine chloride } \\
\hline & Contraction $^{*}$ & $\mathrm{EC}_{\text {so }}$ & Maximal response \\
\hline & $g$ & $-\log M$ & $\%$ \\
\hline Control $(n=2)$ & $5.5 \pm 0.2$ & $6.8 \pm 0.5$ & $20 \pm 10$ \\
\hline \multicolumn{4}{|l|}{$\begin{array}{r}\text { In the presence of } \\
\text { Verapamil } 10^{-9}\end{array}$} \\
\hline $\mathrm{M}(n=2)$ & $7.5 \pm 0.5$ & $6.9 \pm 0.1$ & $0 \pm 0$ \\
\hline \multicolumn{4}{|l|}{$\begin{array}{r}\text { In the presence of } \\
\text { Verapamil } 10^{-8}\end{array}$} \\
\hline $\mathbf{M}(n=2)$ & $7.0 \pm 0.4$ & $6.6 \pm 0.3$ & $23 \pm 14$ \\
\hline \multicolumn{4}{|l|}{$\begin{array}{r}\text { In the presence of } \\
\text { Verapamil } 10^{-7}\end{array}$} \\
\hline$M(n=2)$ & $4.9 \pm 0.3$ & $7.2 \pm 0.4$ & $24 \pm 11$ \\
\hline \multicolumn{4}{|c|}{ In the presence of Verapamil $10^{-6}$} \\
\hline $\mathbf{M}(n=2)$ & $4.3 \pm 0.6$ & $6.7 \pm 0.5$ & $26 \pm 11$ \\
\hline
\end{tabular}

* Expressed as the $\mathrm{EC}_{50}$ (concentration of drug, in - $\log \mathrm{M}$, inducing a half-maximal response) and as the maximal response (the tension remaining afrer maximal vasodilation, expressed as a percentage of the initial contraction to norepinephrine).

${ }^{\ddagger}$ Isometric force (measured in grams) generated in response to the $\mathrm{EC}_{50}$ concentration of norepinephrine. 


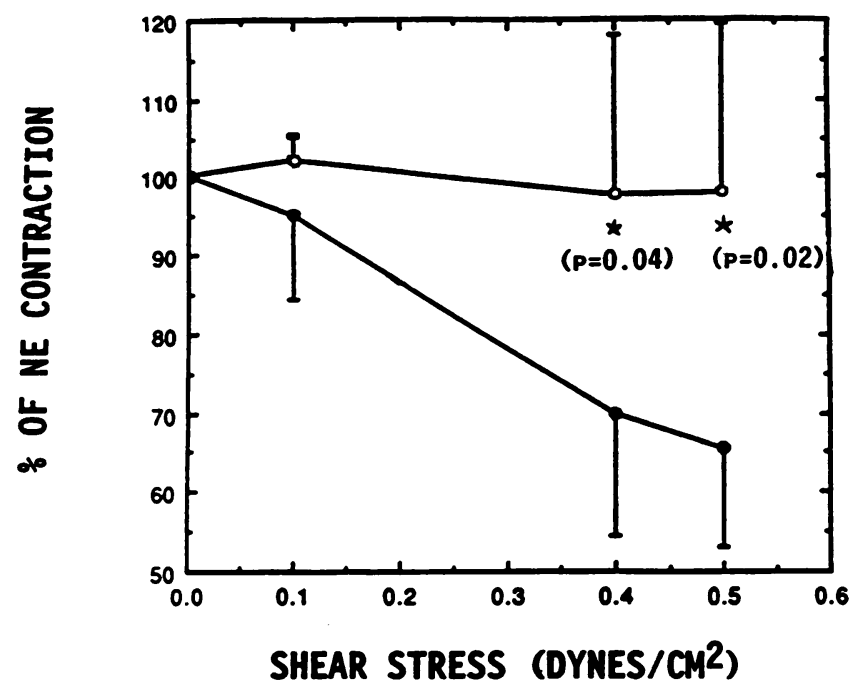

Figure 6. Abolition of flow-mediated vasorelaxation by barium (flow chamber studies). Vascular rings denuded of endothelium were placed in the flow chamber, contracted by norepinephrine $10^{-6} \mathrm{M}$, and then exposed to endothelial cells on microcarrier beads. Until stimulated by flow, endothelial cells in solution did not relax the vascular rings. Increases in flow (inducing endothelial shear stresses in the range of $0.1-0.5 \mathrm{dyn} / \mathrm{cm}^{2}$ ) induced relaxations of the vascular rings in control solution $(\bullet ; n=4)$, but not in the presence of barium $10^{-3} \mathrm{M}(0 ; n$ $=4)$. Relaxation is expressed as a percent of the initial contraction to norepinephrine, $10^{-6} \mathrm{M}(3.2 \pm 1.8$ vs. $4.0 \pm 0.8 \mathrm{~g}$, control vs. barium group, $P=\mathrm{NS}$ ). *Relaxation in the presence of barium is significantly less than that in the presence of vehicle controls.

may set in motion a series of events that leads to the release of nitric oxide, in much the same way that activation of these same channels drives exocrine secretion by mammalian salivary and lacrimal glands $(17,28,29)$.

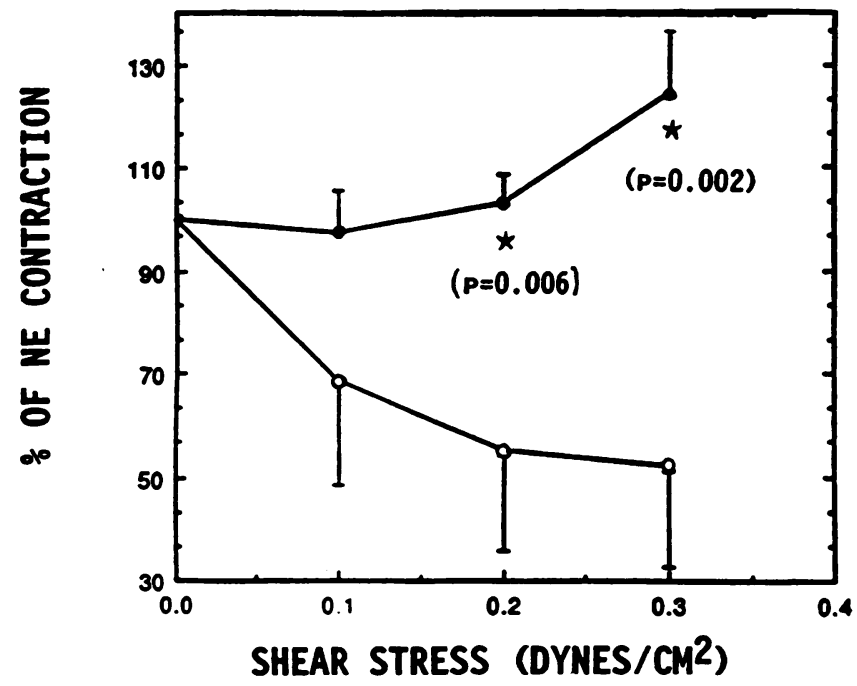

Figure 7. Abolition of flow-mediated vasodilation by charybdotoxin (flow chamber studies). Vascular rings denuded of endothelium were placed in the flow chamber and endothelial cells on microcarrier beads were then added to the solution. Increases in flow (inducing endothelial shear stresses of $0.1-0.3 \mathrm{dyn} / \mathrm{cm}^{2}$ ) induced relaxations of the vascular rings in control solution $(0 ; n=6)$, but not in the presence of charybdotoxin $10^{-8} \mathrm{M}(\bullet ; n=6)$, the specific antagonist of the $\mathrm{K}_{\mathrm{Ca}}$ channel. Relaxation is expressed as a percent of the initial contraction to norepinephrine $10^{-6} \mathrm{M}(3.7 \pm 1.2$ vs. $4.2 \pm 1.7$, control vs. charybdotoxin group, $P=\mathrm{NS}) .{ }^{*}$ Relaxation in the presence of charybdotoxin is significantly less than that in the presence of vehicle controls ( $n=4$ in each group).

A number of groups have suggested that flow-mediated vasodilation is secondary to the release of a substance with the characteristics of nitric oxide. This hypothesis is supported by the observations that removal of the endothelium abrogates

Table V. Effect of Potassium Channel Antagonists on Flow-mediated Relaxation (Flow Chamber Studies)

\begin{tabular}{|c|c|c|c|c|c|}
\hline \multirow[b]{3}{*}{ Condition } & \multirow[b]{3}{*}{ Contraction* } & \multicolumn{4}{|c|}{ Percent contraction ${ }^{\ddagger}$ at each level of shear stress } \\
\hline & & \multicolumn{4}{|c|}{ dynes $/ \mathrm{cm}^{2}$} \\
\hline & & 0 & 0.1 & 0.2 & 0.3 \\
\hline \multicolumn{6}{|c|}{$g$} \\
\hline Control $(n=5)$ & $3.7 \pm 1.2$ & $100 \pm 0$ & $88 \pm 6$ & $73 \pm 0$ & $62 \pm 6$ \\
\hline $\begin{array}{l}\text { In the presence of TEA } \\
\quad(n=5)\end{array}$ & $4.3 \pm 0.7$ & $100 \pm 0$ & $151 \pm 4$ & $\begin{array}{c}152 \pm 40^{5} \\
(P=0.03)\end{array}$ & $\begin{array}{c}160 \pm 32^{8} \\
(P=0.008)\end{array}$ \\
\hline Control $(n=5)$ & $1.5 \pm 0.2$ & $100 \pm 0$ & $88 \pm 6$ & $62 \pm 6$ & $50 \pm 6$ \\
\hline \multicolumn{6}{|l|}{ In the presence of GLY } \\
\hline$(n=5)$ & $2.6 \pm 0.7$ & $100 \pm 0$ & $89 \pm 3$ & $65 \pm 16$ & $60 \pm 10$ \\
\hline Control $(n=2)$ & $3.2 \pm 1.8$ & $100 \pm 0$ & $87 \pm 4$ & $68 \pm 8$ & $54 \pm 8$ \\
\hline \multicolumn{6}{|l|}{ In the presence of $\mathrm{AP}$} \\
\hline$(n=2)$ & $3.0 \pm 1.6$ & $100 \pm 0$ & $80 \pm 6$ & $72 \pm 3$ & $60 \pm 6$ \\
\hline Control $(n=2)$ & $2.6 \pm 0.8$ & $100 \pm 0$ & $90 \pm 3$ & $70 \pm 3$ & $56 \pm 8$ \\
\hline \multicolumn{6}{|l|}{ In the presence of TTX } \\
\hline$(n=2)$ & $3.0 \pm 0.8$ & $100 \pm 0$ & $81 \pm 2$ & $72 \pm 12$ & $62 \pm 6$ \\
\hline Control $(n=5)$ & $4.0 \pm 1.0$ & $100 \pm 0$ & $92 \pm 6$ & $72 \pm 9$ & $62 \pm 6$ \\
\hline \multicolumn{6}{|l|}{ In the presence of OUAB } \\
\hline$(n=5)$ & $3.6 \pm 2.0$ & $100 \pm 0$ & $88 \pm 3$ & $72 \pm 12$ & $54 \pm 16$ \\
\hline
\end{tabular}

* Isometric force generated in response to norepinephrine $\left(10^{-6} \mathrm{M}\right)$, expressed in grams. ${ }^{\ddagger}$ In the presence of endothelial cells on microcarrier beads; expressed as a percentage of the initial contraction to norepinephrine. ${ }^{8}$ Relaxation to the flow stimulus is significantly inhibited in comparison to control ( $P$ value in parentheses). Abbreviations: AP, apamin $\left(10^{-7} \mathrm{M}\right)$; GLY, glybenclamide $\left(10^{-5} \mathrm{M}\right)$; OUAB, ouabain $\left(10^{-6} \mathrm{M}\right)$. 
flow-mediated vasodilation and that exposure of the vessel to methylene blue or eicosatetraenoic acid (agents known to interfere with the action of nitric oxide) also inhibits flow-mediated relaxation $(3-6,30)$. Although prostacyclin is also released by increased flow (31), we have previously demonstrated that aspirin or indomethacin do not inhibit the effects of flowstimulated endothelial cells on platelet or vascular reactivity $(10,13,14)$. Our findings are supported by the previous observation that the perfused canine femoral artery releases a nitric oxide as well as the prostacyclin metabolite, 6-keto-prostaglandin alpha ${ }_{1}$ (32). However, when release of the prostanoid is reduced to negligible levels in the presence of indomethacin, the relaxing activity of the perfusate is unaffected.

The present investigation and our previous studies strongly support the hypothesis that nitric oxide (33) or a similar endogenous nitrovasodilator (34) is the major effector of flow-mediated vasodilation. In this study the antagonist of arginine metabolism, L, $N$-monomethylarginine, abolished this phenomenon. In a previous study, we found that endothelial cells cultured on microcarrier beads released a labile vasodilator when stimulated by flow. The action of this agent was antagonized by methylene blue, hemoglobin, or L, $N$-monomethylarginine (10). Flow-stimulated endothelial cells also inhibited platelet aggregation; this effect was associated with an increase in platelet cyclic GMP and was attenuated by methylene blue $(13,14)$. These studies support a major role for an endogenous nitrovasodilator in the flow phenomenon, but do not exclude participation of the hyperpolarizing current, or other endotheliumderived factors, i.e., the diffusible hyperpolarizing factor (35, 36). In addition to endogenous vasodilators, an endotheliumderived contractile factor also may be released by flow, since inhibitors of nitric oxide or potassium channel activity generally unmasked a vasoconstriction with flow (present investigation, ref. 10).

Other investigators have proposed that flow may have other effects on the endothelial cell membrane that could lead to vasodilation. Measurements of cell membrane potential reveal that membrane stretch (induced by negative pressure applied to the membrane by a microelectrode) induces depolarization of the cell due to opening of a cationic channel (8). However, this channel is not selective, allowing entry of calcium, sodium, potassium, and cesium. Oleson et al. measured membrane potential in endothelial cells lining a glass capillary tube as a function of rates of fluid flow through the lumen. The magnitude of an inwardly rectifying potassium current varied directly and temporally with the rates of flow and was abolished by millimolar concentrations of barium. These investigators proposed that the hyperpolarization of the endothelial cell induced by this potassium current could be transmitted by gap junctions to the underlying smooth muscle, resulting in vasodilation (9).

Our investigation reveals that gap junctions between the endothelial cell and vascular smooth muscle are not necessary for flow-mediated vasodilation. An endogenous nitrovasodilator, rather than a wave of hyperpolarization, appears to be primarily responsible for flow-mediated vasodilation. Our data also suggest that the release of nitric oxide by flow is dependent upon the activation of an endothelial potassium channel, possibly the high conductance calcium-activated potassium channel. We hypothesize that this potassium channel acts as the transducer of the flow stimulus, whereas nitric oxide is the effector of the vasodilation.

\section{Acknowledgments}

We would like to thank Drs. Maria L. Garcia and Gregory J. Kaczorowski of the Department of Membrane Biochemistry, Merck Sharp and Dohme Research Laboratories, for their thoughtful comments and generous donation of charybdotoxin and iberiotoxin, and Dr. Kota Reddy for technical assistance.

This investigation was supported in part by a grant-in-aid from the American Heart Association (Massachusetts affiliate) and an educational grant from Bristol-Myers Squibb Co., New York. Dr. Cooke is a recipient of a National Heart, Lung and Blood Institute Vascular Disease Academic Award HL02660-01.

\section{References}

1. Hilton, S. M. 1959. A peripheral arterial conducting mechanism underlying dilation of the femoral artery and concerned in functional vasodilation in skeletal muscle. J. Physiol. (Lond.) 149:93-111.

2. Lie, M., O. M. Sejersted, and F. Kiil. 1970. Local regulation of vascular cross section during changes in femoral arterial blood flow in dogs. Circ. Res. 27:727-737.

3. Holtz, J., M. Liesler, and E. Bassenge. 1983. Two dilatory mechanisms of antianginal drugs on epicardial coronary arteries in vivo: indirect, flow-dependent endothelium-mediated dilation and direct smooth muscle relaxation. $Z$. Kardiol. Suppl. 72(Suppl. 3):98-106.

4. Hull, S. S., L. Kaiser, M. D. Jaffe, and H. V. Sparks. 1986. Endothelium-dependent flow induced dilation of canine femoral and saphenous arteries. Blood Vessels. 23:183-198.

5. Pohl, V., J. Holtz, R. Busse, and E. Bassenge. 1986. Crucial role of the endothelium in the vasodilator response to increased flow in vivo. Hypertension (Dallas). 8:37-44.

6. Young, M. A., and S. F. Vatner. 1987. Blood flow and endothelium-mediated vasomotion of iliac arteries in conscious dogs. Circ. Res. 61(Suppl. II):II88-II-93.

7. Furchgott, R. F., and J. V. Zawadzki. 1980. The obligatory role of endothelial cells in the relaxation of arterial smooth muscle by acetylcholine. Nature (Lond.). 288:373-376.

8. Lansman, J. B., T. J. Hallam, and T. J. Rink. 1987. Single stretch-activated ion channels in vascular endothelial cells as mechanotransducers. Nature (Lond.) 325:811-813.

9. Oleson, S. P., D. E. Clapham, and P. F. Davies. 1988. Haemodynamic shear stress activates a $\mathrm{K}^{+}$current in vascular endothelial cells. Nature (Lond.). 331:168-170.

10. Cooke, J. P., J. S. Stamler, N. Andon, P. R. Davies, and J. Loscalzo. 1990. Flow stimulates endothelial cells to release a nitrovasodilator that is potentiated by reduced thiol. Am. J. Physiol. [Heart Circ. Physiol.] 28:H804-H812.

11. Yamamoto, H., C. Bossaller, J. Cartwright, Jr., and P. D. Henry. 1988. Videomicroscopic demonstration of defective cholinergic arteriolar vasodilation in atherosclerotic rabbit. J. Clin. Invest. 81:1752-1758.

12. Davies, P. F., G. A. Truskey, H. B. Warren, S. E. O'Connor, and B. H. Eisenhaure. 1985. Metabolic cooperation between vascular endothelial cells and smooth muscle cells in co-culture: changes in low density lipoprotein metabolism. J. Cell Biol. 101:871-879.

13. Stamler, J., M. E. Mendelsohn, P. Amarante, D. Smick, N. Andon, P. R. Davies, J. P. Cooke, and J. Loscalzo. 1989. N-acetylcysteine potentiates platelet inhibition by endothelium-derived relaxing factor. Circ. Res. 65:789-795.

14. Cooke, J. P., J. Stamler, N. A. Andon, P. F. Davies, M. E. Mendelsohn, and J. Loscalzo. 1990. Flow-mediated endothelium-dependent effects on platelet and vascular reactivity. In Endothelium-derived relaxing factors. G. M. Rubanyi and P. M. Vanhoutte, editors. Karger, Basel, Switzerland 244-253.

15. Cooke, J. P., J. T. Shepherd, and P. M. Vanhoutte. 1988. Vasoconstriction induced by ouabain in the canine coronary artery: contribution of adrenergic and non-adrenergic responses. Cardiovasc. Drugs Ther. 63:718-725.

16. Cook, N. S. 1988. The pharmacology of potassium channels and their therapeutic potential. Trends Pharmacol. Sci. 9:21-28.

17. Petersen, O. H. 1986. Calcium-activated potassium channels and fluid secretion by exocrine glands. Am. J. Physiol. 251 (Gastrointest. Liver Physiol. 14):G1-G13.

18. Findlay, I., M. J. Dunne, S. Ullrich, C. B. Wollheim, and O. H. Petersen. 1985. Quinine inhibits $\mathrm{Ca}^{2+}$-independent $\mathrm{K}^{+}$channels whereas tetraethylammonium inhibits $\mathrm{Ca}^{2+}$-activated $\mathrm{K}^{+}$channels in insulin-secreting cells. FEBS (Fed. Eur. Biochem. Soc.) Lett. 185:4-8.

19. Gimenez-Gallego, G., M. A. Navia, J. P. Reuben, G. M. Katz, G. J. Kaczorowski, and M. L. Garcia. 1988. Purification, sequence, and model structure of charybdotoxin, a potent selective inhibitor of calcium-activated potassium channels. Proc. Natl. Acad. Sci. USA. 85:3329-3333. 
20. Hermann, A., and C. Erxleben. 1987. Charybdotoxin selectively blocks small Ca-activated K channels in Aplysia neurons. J. Gen. Physiol. 90:27-47.

21. Christie, M. J., J. P. Adelman, J. Douglass, and R. A. North. 1989. Expression of a cloned rat brain potassium channel in Xenopus oocytes. Science (Wash. DC). 239:771-775.

22. Lewis, R. S., and M. D. Cahalan. 1988. Subset-specific expression of potassium channels in developing murine T lymphocytes. Science (Wash. DC). 239:771-775.

23. MacKinnon, R., Ph. H. Reinhart, and M. M. White. 1988. Charybdotoxin block of Shaker $\mathrm{K}^{+}$channel suggests that different types of $\mathrm{K}^{+}$channels share common structural features. Neuron. 1:997-1001.

24. Galvez, A., G. Gimenez-Gallego, J. P. Reuben, L. Roy-Contancin, P. Feigenbaum, G. J. Kaczorowski, and M. L. Garcia. 1990. Purification and characterization of a unique, potent, peptidyl-probe for the high-conductance calciumactivated potassium channel from venom of the scorpion, Buthus tamulus. J. Biol. Chem. 265:11083-11090.

25. Maruyama, Y., O. H. Petersen, P. Flanagan, and G. T. Pearson. 1983 Quantification of $\mathrm{Ca}^{2+}$-activated $\mathrm{K}^{+}$channels under hormonal control in pig pancreas acinar cells. Nature (Lond.). 305:228-232.

26. Pearson, G. T., P. M. Flanagan, and O. H. Petersen. 1984. Neural and hormonal control of membrane conductance in the pig pancreatic acinar cell. Am. J. Physiol. 247(Gastrolintest. Liver Physiol. 10):G520-G526.

27. Walsh, J. V., and J. J. Singer. 1987. Identification and characterization of major ionic currents in isolated smooth muscle cells using the voltage-clamp technique. Pflugers Arch. Eur. J. Physiol. 408:83-97.

28. Maruyama, R., D. V. Gallacher, and O. H. Petersen. 1983. Voltage and $\mathrm{Ca}^{2+}$-activated $\mathrm{K}^{+}$channel in baso-lateral acinar cell membranes of mammalian salivary glands. Nature (Lond.). 302:827-829.
29. Petersen, O. H., and Y. Maruyama. 1984. Calcium-activated potassium channels and their role in secretion. Nature (Lond.). 307:693-696.

30. Kaiser, L., S. S. Hull, Jr., and H. V. Sparks, Jr. 1986. Methylene blue and ETYA block flow-dependent dilation in canine femoral artery. Am. J. Physiol. 250:H974-H981.

31. Frangos, J. A., S. G. Eskin, L. V. McIntire, and C. L. Ives. 1984. Flow effects on prostacyclin production by cultured human endothelial cells. Science (Wash. DC). 227:1477-1479.

32. Rubanyi, G. M., J. C. Romero, and P. M. Vanhoutte. 1986. Flow-induced release of endothelium derived relaxing factor. Am. J. Physiol. 250:H1145H1149.

33. Palmer, R. M. J., A. G. Ferridge, and S. Moncada. 1987. Nitric oxide release accounts for the biological activity of endothelium-derived relaxing factor. Nature (Lond.). 327:524-526.

34. Myers, P. R., R. L. Minor, Jr., R. Guerra, Jr., J. N. Bates, and D. G. Harrison. 1990. Vasorelaxant properties of the endothelium-derived relaxing factor more closely resemble S-nitrosocysteine than nitric oxide. Nature (Lond.). 345:161-163.

35. Feletou, M., and P. M. Vanhoutte. 1988. Endothelium-dependent hyperpolarization of canine coronary smooth muscle. Br. J. Pharmacol. 93:515-524.

36. Komori, K., R. R. Lorenz, and P. M. Vanhoutte. 1988. Nitric oxide, ACh, and electrical and mechanical properties of canine arterial smooth muscle. $A m$. J. Physiol. 255:H207-H212.

37. Kenakin, T. P. 1987. Methods of drug and receptor classification. In Pharmacological Analysis of Drug-Receptor Interaction. T. P. Kenakin, editor. Raven Press, New York. 263-264. 